* Doutor pela Universidade Federal de Santa Catarina; Mestre pela UGF; Coordenador-Adjunto e professor do PPGD -UNESA e Professor do PPGD - UNESA, vinculado à linha de pesquisa de Direitos Fundamentais e Novos Direitos, com projetos nas áreas: sociedade da informação e a função social da propriedade: material e imaterial, e Inovação tecnológica e desenvolvimento ambiental sustentável. Advogado, Professor Adjunto da Universidade Federal Fluminense - UFF e Professor Titular do PPGD - UNESA. E-mail: cesarflores2004@hotmail.com

** Doutoranda em Direito pela Estácio de Sá do RJ. Mestre em Direito Público pela UNISINOS. Especialista em Direito do Trabalho e Processo do Trabalho pela IMED/RS. Advogada Trabalhista. Coordenadora do Programa de Pós Graduação em Direito do Trabalho e Direito Previdenciário da FEMA - RS. Professora do curso de Direito da FEMA/ RS. Técnica em Segurança do Trabalho. E-mail: dani.terribile@hotmail.com

\section{Ética ocupacional sustentável numa sociedade globalizada}

\section{OCCUPATIONAL ETHICS SUSTAINABLE A GLOBAL SOCIETY}

\author{
* Nilton Cesar Flores \\ ** Daniele Regina Terribile
}

Resumo: A temática meio ambiente de trabalho reproduz as complexidades dos riscos no mundo globalizado. No imbricar da inter-relação deste movimento de globalização da economia e da reestruturação produtiva que se desencadeia uma série de consequências sociais. Ao passo que a globalização e o surgimento de novas tecnologias beneficiaram o homem, em contrapartida, deram-se à custa de uma margem de descaso e negligência à integridade dos envolvidos no processo. Assim, surge a necessidade de novas abordagens do Direito. Para tanto, o estudo supera a teoria da ecologia rasa e parte da compreensão da teoria da ecologia profunda, sem que esta perca sua essência, propondose uma análise focada no elemento homem dentro da teia da vida, indicando um novo princípio norteador: por uma ética ocupacional sustentável.

Palavras-chave: Globalização. Meio ambiente de trabalho. Novos Direitos. Risco. Sustentabilidade.

Abstract: The thematic working environment reproduces the complexities of the risks in a globalized world. Imbricate in the interrelationship of the movement of economic globalization and the restructuring of production that triggers a series of social consequences. While globalization and the emergence of new technologies have benefited the man, however, occurred at the expense of a degree of contempt and neglect the integrity of those involved in the process. Thus, the need for new approaches to the Law arises. Thus, the study overcomes the theory of shallow understanding of the ecology and the theory of deep ecology without it looses its essence, proposing a focused element in man in the web of life analysis, indicating a new guiding principle for sustainable occupational ethics.

Keywords: Globalization. New Rights. Risk. Sustainability. Working Environment. 


\section{INTRODUÇÃO}

O avanço tecnológico e científico substitui/cria máquinas, substâncias e outros riscos que impactam de forma negativa no ambiente de trabalho, exigem cada vez mais produtividade, maiores exposições e conduzindo o meio ambiente de trabalho à degradação. A meta do ganho no capitalismo globalizado é fator determinante para a sobrevivência no mercado. Essa sobrevivência é ditada pela aplicação de novas tecnologias, aceleradas formas de produção e custos de fabricação menores que os competidores. Por sua vez, a diminuição dos custos é regida essencialmente pelo menosprezo aos direitos sociais, em especial, ao meio ambiente ecologicamente equilibrado.

A deterioração da saúde e da vida humana no meio ambiente de trabalho é uma realidade para a qual poucos setores da sociedade estão preocupados. As pesquisas, a nível nacional, demonstram que a produção a todo custo é levada a sério com todo o fervor exigido pelo capitalismo. A fomentação da economia através da produção e imediato consumo de produtos, cada vez mais inovadores, esconde uma realidade negra para a qual nem consumidor e sequer governo estão, de fato, conscientes das consequências, sejam elas humanas ou econômicas.

As estatísticas previdenciárias dão conta que o número de lesões e óbitos no meio ambiente de trabalho estampa uma epidemia que necessita de urgente repensar de valores e demandam novos direitos. Para tanto, partindo-se da compreensão da teoria da ecologia profunda, e sem que esta perca sua essência, propõe-se uma análise focada no elemento homem dentro da teia da vida.

\section{GLOBALIZAÇÃO E DESENVOLVIMENTO ECONÔMICO: DA REESTRUTURAÇÃO PRODUTIVAAOS NOVOS RISCOS NO MEIO AMBIENTE DE TRABALHO}

A ascensão do processo de globalização, iniciado no final do século XX e intensificado no século XXI, ampliou as relações além-fronteiras, permitiu interações transnacionais de produção e capital, disseminou os meios de comunicação a nível mundial, permitiu a facilidade de deslocamento de pessoas e promoveu profundas alterações no mercado de trabalho.

Giddens define globalização como sendo a intensificação de relações sociais mundiais que unem localidades distantes de tal modo que os 
acontecimentos locais são condicionados por eventos que acontecem a muitas milhas de distância e vice-versa. (GIDDENS, 1990, p. 64). Santos refere que a globalização econômica é sustentada pelo consenso econômico neoliberal, cuja inovação é a restrição drástica à regulação estatal da economia. (SANTOS, 2002, p. 31). Assim, a estrutura da economia capitalista avança do espaço nacional para um mundo sem fronteiras, em que a referência para ações estratégicas de desenvolvimento não se limitam a soberania dos territórios, mas sim, a livre concorrência de mercados a nível mundial.

Conceituando, genericamente, a globalização é o aprofundamento da interação entre países nos aspectos econômicos, sociais, culturais e políticos. Suas mudanças foram sentidas em todos os países, ainda que em diferentes graus. Como bem destaca Santos, ela surgiu como um processo "hegemônico num vasto e intenso campo de conflitos” (SANTOS, 2002, p. 72), no qual as dimensões econômicas, sociais, políticas e jurídicas interligam-se de modo complexo.

No campo da economia, a globalização gerou profundas alterações, ao permitir a expansão do capitalismo. Esse movimento foi possível graças aos avanços tecnológicos da informática e das comunicações que permitiram alterações na dimensão produtiva e a realização de transações financeiras, em tempo real, em mercados até então considerados distantes e não competitivos. Na visão de Castells "uma revolução tecnológica, centrada nas tecnologias da informação começou a remodelar a base material da sociedade em ritmo acelerado”. (CASTELLS, 1999. p.39).

Uma das principais características da ascensão do capitalismo a nível global foi à reestruturação de todo o processo de produção. Baseada no fordismo (BAUMAN, 2001, p.151) - tylorismo - período da produção em massa de produtos homogêneos (ANTUNES,1999, p.17) - a produção adquire a estrutura do toyotismo - produção enxuta, de produtos variados, com obtenção da máxima intensidade do trabalho e o máximo rendimento da mão de obra. Esse novo modelo de produção surgiu adequado à lógica do mercado, dos seus produtos e padrões de consumo. Não mais se sustenta a visão fordista-tylorista e busca-se um processo rápido e vantajoso de produção de mercadorias, em variedade, através do uso de novas substancias decorrentes das novas tecnologias.

Na obra intitulada a corrosão do caráter, Sennett aborda que o atual capitalismo flexível pede ao trabalhador agilidade, abertura a mudanças em curto prazo e que assuma, de forma contínua, riscos, ainda que não saiba que 
esses riscos existam. De forma natural, a imprensa e a classe empresarial destacam o uso de novas tecnologias como características distintivas do capitalismo de nossa época. (SENNETT, 2012, p. 9).

Assim, em resposta à demanda global do capitalismo, a classe empregadora adota medidas visando reestruturar seu capital e produção para sobreviver e ganhar competitividade no mercado mundial. Tais medidas de reestruturação vêm acompanhadas de ônus sociais elevadíssimos que agravam ainda mais a economia, tendo como principais características a precarização da saúde no meio ambiente de trabalho. Os "ganhos" trazidos pelo capitalismo podem estar se dirigindo por caminhos suspeitos

A passagem da sociedade industrial para a sociedade de riscos é marcada por uma etapa de uma ruptura dentro da modernidade. A sociedade industrial clássica foi substituída por uma sociedade em que os riscos - sejam eles industriais, políticos, sociais e econômicos - encaminham-se em proporções cada vez maiores fugindo do controle das instituições. Estes dois espaços são denominados por Beck, respectivamente de modernização tardia - modernização simples - e modernização da sociedade industrial - ou modernização reflexiva. (BECK, 2010)

A sociedade industrial produz riscos de natureza específica, tratando-se de riscos que, além de serem perceptíveis antecipadamente, apresentam certa visibilidade na lógica de causa e consequência. (CARVALHO, 2008). A transição da modernização simples para a modernização tardia gerou riscos invisíveis e deslocou a circunsferência da noção do risco, uma vez que passaram a ser traçados no futuro e não no presente como ocorria na sociedade industrail clássica. Consequentemente, a projeção do risco para o futuro exige das ciências a capacidade de o reconhecer para torná-lo legítimo e assim poder enfrentá-lo. Contudo, o surgimento dessa nova sociedade de risco e de seus problemas consequentes ainda esbarram em decisões e discursos de uma estrutura montada lá na sociedade industrial clássica.

Ao passo que a globalização e o surgimento de novas tecnologias beneficiaram o homem, em contrapartida, deram-se à custa de uma margem de descaso e negligência à integridade dos envolvidos no processo. Nesse sentido, no transcorrer da trajetória da civilização, alguns riscos inerentes a determinadas atividades apenas foram conhecidos e estudados após a consumação de suas consequências.

De acordo com a OMS, os riscos ao meio ambiente do trabalho constituem uma ameaça para larga faixa da população mundial, motivo pelo qual a saúde 
se ocupa com as diversas modalidades de riscos ambientais para o trabalhador. (FIGUEIREDO, 2003). No meio em que o trabalhador presta seu labor interagem diversos riscos resultantes dos meios de fabricação. Os novos padrões de produção aliados ao desenvolvimento tecnológico delinearam mudanças no meio e na forma em que o labor é exercido.

As necessidades de aprimoramentos das empresas na inovação e criação de novos produtos para acompanhar as ofertas/demandas do mercado têm como pano de fundo a manipulação de substâncias e operações que oferecem alto grau de risco aos envolvidos no processo. Os riscos ambientais - ou agentes ambientais - dispersos no local de trabalho vão além da conceituação de riscos concretos da sociedade industrial clássica. A sociedade de risco apresenta uma infinidade de riscos invisíveis que permeiam os postos e estabelecimentos de trabalho.

Nesse aspecto, a globalização se encontra intrinsecamente ligada à saúde por meio da conjugação de aspectos negativos e desafios. A área escura da globalização está associada ao que se poderia denominar de "efeitos residuais" surgidos da necessidade que os países se conformem as receitas econômicas internacionais. Surgem aqui as condições ligadas à inserção de um poderoso setor privado, à deterioração das condições de trabalho. (BOLIS, 2003, p.19)

A questão do meio ambiente de trabalho espelha complexidades do mundo contemporâneo que se defrontam com a ampliação do problema que se tornou global, requerendo intervenção que não interponha obstáculo ao desenvolvimento econômico e sustente garantia de direitos das gerações atuais e das futuras. (DERANI, 1997, p.71)

Para Nilton, pode-se afirmar que a lógica da economia e dos princípios econômicos seguem diretrizes de um mercado, que está sempre buscando otimizar lucros e reduzir os custos.(NILTON, 2012, p. 272). Nesse sentido, para Magalhães, a construção da sociedade de consumo em que vivemos nos mergulha em valores que comprometem a vida humana no planeta, substituindo radicalmente os valores que sustentam as relações humanas. (MAGALHÃES, Ano 15, p. 168).

O desenvolvimento do capitalismo implicou na invasão de territórios em todo o mundo para a exploração de diversos recursos da terra, além da exploração do trabalho. Não haveria capitalismo sem estado, sem guerra, exploração da natureza e do trabalho animal (neste incluído o do homem). (MAGALHÃES, Ano 15, p. 167). 
Para melhor compreender, quanto ao Risco Químico, à preocupação demonstrada pela Organização Mundial da Saúde - OMS - é com o uso de mais de cem mil diferentes produtos químicos no moderno meio ambiente de trabalho. Os efeitos na constituição física dos seres humanos se fazem sentir no envenenamento por metais, nas lesões no sistema nervoso central e no fígado, no envenenamento por pesticidas, nas alergias dérmicas e respiratórias, nas dermatoses, no câncer e nos distúrbios reprodutivos. (FIGUEIREDO, 2003, p.60). Dos mais de 100 agentes, substâncias e misturas comprovadamente cancerígenas para humanos, mais de 30 são associadas especificamente ao câncer ocupacional. (REIMBERG, 2011, p.38).

Bem declarou Beck que na modernidade avançada, a produção social de riqueza é sistematicamente acompanhada pelas produções sociais de riscos. (BECK, 1992, p.19). Para exemplificar, a exposição dos trabalhadores ao Risco Biológico, com as novidades em manipulações laboratoriais emergiram em um número ainda maior de fungos, parasitas, protozoários e vírus que não raramente sofrem mutações e tornam-se ainda mais agressivos.

O Risco Ergonômico, por sua vez, tem sido apontado como o grande vilão das doenças ocupacionais. (BRASIL, 2010). A realidade de constantes lesões por esforços repetitivos reflete as cobranças produtivas impostas aos trabalhadores, originárias da exigibilidade do mercado econômico.

O que também deve gerar preocupação pela sua intensificação é a exposição dos trabalhadores aos Riscos Físicos. Com a necessidade de se criar ambientes cada vez mais propícios ao aumento de produção, o mercado utiliza-se de recursos com fontes de calor, resfriamento, umidades, radiações, intensidades de ruído, poeiras, névoas e neblinas.

A uniformização do direito e do comportamento que sustentam a globalização de um sistema econômico egoísta e excludente é a marca desta modernidade.[..] a natureza, nestes últimos quinhentos anos, tem sido vista como dissociada da sociedade humana, servindo para abastecer, esta sociedade, de "recursos" necessários para alimentar o desejo incontrolável de consumo de bens, de produtos. (MAGALHÃES, Ano 15, p. 175).

Enfrentamos agora uma nova ameaça à nossa sobrevivência. A proliferação de seres humanos, associada aos resíduos do crescimento econômico, é a receita capaz de varrer a nossa sociedade da face da terra como as velhas ameaças tradicionais. ( SINGER, 2002). O foco do 
“desenvolvimento” necessita ser percebido com outra ótica. Os conceitos necessitam ser revistos.

\section{A ANÁLISE DO HOMEM INSERIDO NA PERSPECTIVA DA ECOLOGIA PROFUNDA}

A degradação da saúde e da vida humana no meio ambiente de trabalho é uma realidade para a qual poucos setores da sociedade estão preocupados. As pesquisas, a nível nacional, demonstram que a produção a todo custo é levada a sério com todo o fervor exigido pelo capitalismo.

A política crescimentista adotada pelo atual governo brasileiro e pela maioria dos demais países atende o padrão do mercado. O noticiário diário destaca nos índices de crescimento da economia, PIB, uma ostensiva estimulada corrida entre países. A ordem é crescer e, de preferência, aceleradamente. (LOURENÇO, 2012,p.287)

A fomentação da economia através da produção e imediato consumo de produtos, cada vez mais inovadores, esconde uma realidade negra para a qual nem consumidor e sequer governo estão, de fato, conscientes das consequências, sejam elas humanas ou econômicas.

As estatísticas previdenciárias dão conta que, entre os anos de 2010, 2011 e 2012, o Brasil registrou, formalmente, entre acidentes de trabalho e doenças ocupacionais, o número de 2.135,342 (dois milhões cento e trinta e cinco mil com trezentos e quarenta e dois) casos. A esse absurdo deve-se, ainda, somar a cifra de acidentes e doenças não registrada, sonegada, subnotificada pelas empresas, que, segundo estimativas da previdência social, alcançaram à média, no mesmo triênio de mais 520.374 (quinhentos e vinte mil com trezentos e setenta e quatro) vítimas. Totalizando 2.655,716 (dois milhões seiscentos e cinquenta e cinco com setecentos e dezesseis) casos de lesões ocupacionais.

Desse número total, 8.422 (oito mil quatrocentos e vinte e dois) trabalhadores fizeram óbito e 47.355 (quarenta e sete mil trezentos e cinquenta e cinco) restaram incapacitados de forma permanente para o mercado de trabalho,(BRASIL, 2012) gerando um custo assombroso para a sociedade.

Epidemia? Absurdo? Esses números não dizem respeito a catástrofes ambientais ou guerras mundiais. Ademais, esses dados não se referem a estatísticas mundiais e de décadas. Referem-se, simplesmente, aos últimos 
triênios do Brasil. Aqui não se mencionou os casos da China, dos Estados Unidos, e demais regiões do planeta. Aliás, um estudo desenvolvido pela Organização Internacional do Trabalho (OIT) e Organização Mundial de Saúde (OMS), prevê uma subnotificação nos registros de acidentes de trabalho da ordem de 92\% só na América Latina.

Talvez ousado, mas interessante analisar, aqui, a doutrina ambiental de Capra. O autor bem destaca que defrontamo-nos com toda uma série de problemas globais que estão danificando a biosfera e a vida humana de uma maneira alarmante, e que pode logo se tornar irreversível. (CAPRA, 2006, p. 14). Esses problemas precisam ser vistos, exatamente, como diferentes facetas de uma única crise, que é, em grande medida, uma crise de percepção.(CAPRA, 2006, p. 14). A crise de percepção que o autor menciona refere-se à forma como o homem percebe o meio ambiente.

O novo paradigma pode ser chamado de uma visão de mundo holística, que concebe o mundo como um todo integrado, e não como uma coleção de partes dissociadas. Pode também ser denominado visão ecológica, se o termo "ecológica" for empregado num sentido muito mais amplo e mais profundo que o usual. A percepção ecológica profunda reconhece a interdependência fundamental de todos os fenômenos, e o fato de que, enquanto indivíduos e sociedades, estamos todos encaixados nos processos cíclicos da natureza (e, em última análise, somos dependentes desses processos). [...] Uma visão holística, digamos, de uma bicicleta significa ver a bicicleta como um todo funcional e compreender, em conformidade com isso, as interdependências das suas partes. Uma visão ecológica da bicicleta inclui isso, mas acrescenta-lhe a percepção de como a bicicleta está encaixada no seu ambiente natural e social — de onde vêm as matérias-primas que entram nela, como foi fabricada, como seu uso afeta o meio ambiente natural e a comunidade pela qual ela é usada, e assim por diante. (LOURENÇO, 2012, p.299). (grifo nosso)

A forma como Capra alcança o meio ambiente ultrapassa a visão antropocêntrica, onde o homem o preserva para a garantia de sobrevivência das futuras gerações. Destaca que a ecologia rasa é antropocêntrica, ou centralizada no ser humano. Ela vê os seres humanos como situados acima ou fora da natureza, como a fonte de todos os valores, e atribui apenas um valor instrumental, ou de "uso", à natureza. (LOURENÇO, 2012, p.299). Preservase o meio ambiente como garantia futura de sobrevivência. Não fosse essa a preocupação, o meio ambiente não seria pauta de inquietações. 
Por sua vez, a ecologia profunda não separa seres humanos ou qualquer outro ser ou coisa do meio ambiente natural. O ser humano é apenas mais um elemento que compõe esse meio. Na ecologia profunda, o mundo não é uma coleção de objetos isolados, mas uma rede de fenômenos que estão fundamentalmente interconectados e são interdependentes. A ecologia profunda reconhece o valor intrínseco de todos os seres vivos e concebe os seres humanos apenas como um fio particular na teia da vida. (LOURENÇO, 2012, p.299).

A Ecologia Rasa estaria inserida primariamente no paradigma antropocêntrico e teria por objetivo proteger o meio ambiente como meio para assegurar o fim de bem-estar humano. Quebrando o paradigma antropocêntrico a Ecologia Profunda, por sua vez, compromete-se com a ideia de que a relação entre homem e natureza é holística.(LOURENÇO, 2012, p.299).

Partindo-se da compreensão da teoria da ecologia profunda, e sem que esta perca sua essência, propõe-se uma análise focada no elemento homem dentro da teia da vida. Reitera-se que não se está considerando proteger o meio ambiente com o fim único de assegurar o bem estar dessa espécie, como faz a ecologia rasa. A apreciação, aqui, parte da perspectiva da proteção do homem, dentro da teia da vida, no atual cenário em que este se encontra. $\mathrm{O}$ resguardo do componente humano é em face da própria autodestruição.

Todos os membros de uma comunidade ecológica estão interligados numa vasta e intrincada rede de relações, a teia da vida. Eles derivam suas propriedades essenciais, e, na verdade, sua própria existência, de suas relações com outras coisas. A interdependência — a dependência mútua de todos os processos vitais dos organismos - é a natureza de todas as relações ecológicas. O comportamento de cada membro vivo do ecossistema depende do comportamento de muitos outros. O sucesso da comunidade toda depende do sucesso de cada um de seus membros, enquanto que o sucesso de cada membro depende do sucesso da comunidade como um todo.(CAPRA, 2006, p. 219).

Se a ecologia profunda propõe a análise do meio ambiente integrado, onde todos os seres são interligados e com o mesmo grau de importância dentro do enredo de vida, a análise tenta resgatar e proteger a espécie do homem em face ao próprio homem. Vários são os focos de destruição em massa da espécie humana. Variadas são as maneiras de degradação dessa forma de vida. No 
entanto, existe um modo silencioso, argucioso e não perceptível de aniquilamento do objeto humano: as atuais condições do meio ambiente de trabalho.

Sob um ponto de vista mais profundo, filosófico e sociológico se questionaria a origem do trabalho e sua relação de (des)necessidade dentro da teia da vida. Estaria Beck correto em mencionar que "através do buraco de agulha de seu emprego o profissional se torna um co-reformador do mundo em pequena escala”? (BECK, 2010, p. 204). Por ora e de forma mais superficial, parte-se de um cenário ocupacional de extermínio humano já constituído no meio ocupacional. Um quadro de degradação humana em prol de um doentio “desenvolvimento" econômico inconsequente.

O conjunto de valores e proibições éticos adotados pela ética de sociedades específicas refletirá sempre as condições nas quais têm de viver e de trabalhar para sobreviver. (SINGER, 2002). Ao trabalho atribuiu-se muitas virtudes e efeitos benéficos, como, por exemplo, o aumento da riqueza e a eliminação da miséria e, acima de tudo sua suposta contribuição para o estabelecimento da ordem, para o ato histórico de colocar a espécie humana no comando de seu próprio destino. (BAUMAN, 2001, p.157).

As doenças, acidentes e mortes no trabalho, constituem efeitos indesejados de um sistema de produção que elegeu como valor maior a lucratividade e o seu próprio crescimento em lugar do bem estar social. (FIGUEIREDO, 2003). O desenvolvimento econômico não pode ser dissociado da necessidade de proteção dos ambientes de trabalho. Por mais que os processos do trabalho possam ser aprimorados, o trabalhador deve ter o direito de exercer suas atividades em um meio ambiente de trabalho que lhe possibilite o bem estar e a vida com qualidade. (ROCHA, 2002).

O respeito ao meio ambiente deve ser analisado sob o ponto de vista ético e não mais meramente econômico. (LOURENÇO, 2012, p.300). A realidade dos danos decorrentes do meio ambiente de trabalho está a exigir uma ferramenta mais eficiente e capaz de precaver, não apenas os riscos concretos, mas inclusive os novos riscos, que pela sua imprevisão, tornam-se complexos.

A sociedade atual observa a produção tanto dos riscos oriundos do maquinismo e da Revolução Industrial (que são os riscos concretos, dotados de uma lógica causal mais simples, tais como os riscos inerentes à operação de uma máquina de corte), quanto de novos riscos, mais abstratos e complexos. Por essa exata razão, não apenas é necessária a utilização da 
responsabilidade civil como instrumento de reparação de danos (e, indiretamente, prevenção), como ocorre em sua acepção clássica (teoria do risco concreto, como fundamento dogmático para a imputação objetiva), mas também como elemento jurídico de gestão de riscos ambientais (teoria do risco abstrato), com incidência anterior à ocorrência e efetivação dos danos ambientais, impondo o cumprimento de medidas preventivas ao agente (obrigação de fazer e não fazer) (CARVALHO, 2008).

Ao passo que o moderno capitalismo é consequência imediata à volatilidade da demanda do consumidor, onde se tenta pôr, cada vez mais rápido produtos mais variados no mercado (SENNETT, 2012, p. 57), a concepção de desenvolvimento econômico na matriz da Ecologia Profunda proclama um progresso qualitativo e não apenas quantitativo, a contraposição ao consumismo, pauta-se pelo necessário. (LOURENÇO, 2012, p.286).

Neste breve esboço do paradigma ecológico emergente, enfatizei até agora as mudanças nas percepções e nas maneiras de pensar. Se isso fosse tudo o que é necessário, a transição para um novo paradigma seria muito mais fácil. Há, no movimento da ecologia profunda, um número suficiente de pensadores articulados e eloqüentes que poderiam convencer nossos líderes políticos e corporativos acerca dos méritos do novo pensamento. Mas isto é somente parte da história. A mudança de paradigmas requer uma expansão não apenas, de nossas percepções e maneiras de pensar, mas também de nossos valores. (CAPRA, 2006, p. 18).

Na visão ecologia profunda, a vida se encontra em seu próprio cerne. (CAPRA, 2006, p. 20).Dentre os princípios básicos sobre os quais se apoia essa teoria, destaca-se que a necessidade de mudança ideológica que consista em uma nova percepção sobre a qualidade de vida e não na promoção de padrões de vida cada vez mais altos. E que para tanto, as políticas públicas devem ser rapidamente revistas e modificadas. Consequentemente, o resultado das mudanças nas áreas econômica, tecnológica e ideológica promoverá uma situação muito diversa da atual. (DEVALL, 2012, p.299)

A preservação da espécie humana do próprio ambiente de trabalho requer a possibilidade de uma nova visão integrada das duas linhas opostas de pensamento - ecologia rasa e ecologia profunda. Uma teoria pode complementar a outra. Se na ecologia profunda busca-se preservar a natureza e todas as suas espécies de forma interligada, pode-se, então, partindo dessa visão, aprofundar a ideia de preservação para cada diferente espécie que compõe essa teia, de 
forma que uma não desmereça a outra, ao contrário, que cada qual possa se complementar e, acima de tudo, que cada espécie em sua individualidade não promova sua autodestruição.

Para que essa preservação ocorra, o homem deve partir da compreensão do valor inerente da natureza e dele enquanto apenas mais um elemento da teia da vida, com direito humano ao meio ambiente ecologicamente equilibrado, assim como qualquer outra espécie, mas de forma a não cair na tentação da posição antropocêntrica. Isso somente seria possível a partir de uma mudança drástica de valores. A começar, por uma ética ocupacional sustentável, capaz privilegiar, na produção e consumo de bens, a totalidade do meio ambiente, com suas espécies e diversidades.

\section{MEIO AMBIENTE DE TRABALHO E SUSTENTABILIDADE: O DESENVOLVIMENTO DE UMA ÉTICA OCUPACIONAL SUSTENTÁVEL}

O desenvolvimento de uma ética ambiental sustentável, capaz de reunir em seu rol de tutela, além de todas as espécies que compõe o sistema, a saúde e integridade do trabalhador, frente aos novos riscos decorrentes dos novos processos produtivos requer a visualização do homem como um elemento/parte integrante da sustentabilidade profunda.

Não se está voltando ao discurso da sustentabilidade antropocêntrica ou ecologia rasa. Muito pelo contrário. Se o homem, na ecologia profunda, constitui um ser/elemento do sistema, este deve ser tutelado frente às agressões do ambiente de trabalho produzidas por sua própria espécie.

Não se pretende aqui defender o meio ambiente para que as futuras gerações possam dele usufruir. Essa é a grande distinção. Compreender a distinção entre a preservação do homem no ambiente em face de uma sustentabilidade extremamente e egoisticamente antropocêntrica, que pretende preservar para futuramente usufruir é a essência, o objetivo que se pretende.

Lutando pela salubridade do meio ambiente de trabalho está-se, diretamente, atingindo a consciência ecológica profunda. Muito além de preservar uma espécie - humana - a diminuição e uso racional, no meio ocupacional, de novas substâncias e novas tecnologias, alcançada através de um consumidor mais consciente e prudente diminuirá, gradativamente, a produção de lixo, contaminação de efluentes, surgimento de novos riscos 
desconhecidos, permitindo a sobrevivência das demais espécies da teia da vida. Muito além de beneficiar o homem, a integridade da biosfera unicamente por si mesma, com todas suas espécies e elementos preservam-se.

O pensamento ecológico raso estava limitado ao quadro moral tradicional. Desejava-se ardentemente impedir a poluição das resevas de água, de modo a ter água potável para beber. Procurava-se preservar o meio natural de modo que as pessoas pudessem continuar a desfrutar os prazeres da natureza. Por sua vez, os ecologistas profundos queriam preservar a integridade da biosfera unicamente por si mesma, independentemente dos possíveis benefícios para os seres humanos que poderiam daí advir. Ao passo que a ética da reverência pela vida (rasa, superficial) se centra nos organismos vivos individuais, as propostas da ecologia profunda têm tendência para considerar algo mais vasto como objeto de valor: as espécies, os sistemas, a biosfera no seu todo.(SINGER, 2002)

Uma ética antropocêntrica pode constituir a base de argumentos fortes em favor daquilo a que podemos chamar "valor ambientais" Uma ética que não implica que o crescimento econômico seja mais importante que a preservação do meio natural; pelo contrário, é perfeitamente compatível com uma ética antropocêntrica encarar o crescimento econômico baseado na exploração de recursos insubstituíveis como algo que traz ganhos à geração presente e possivelmente a mais uma ou duas gerações seguintes, mas um preço que será pago por todas as gerações do futuro. (SINGER, 2002). O desenvolvimento de uma ética ocupacional sustentável cinge meio ambiente de trabalho salubre, saúde, integridade física e emocional e produção ecologicamente equilibrada.

Mudar o entendimento de que uma sociedade sustentável é aquela que satisfaz suas necessidades sem diminuir as perspectivas das gerações futuras, (CAPRA, 2006, p. 15) e, ainda, ampliar a compreensão, como requer a ecologia profunda, de que "o grande desafio do nosso tempo é criar comunidades sustentáveis - isto é, ambientes sociais e culturais onde podemos satisfazer as nossas necessidades e aspirações sem diminuir as chances das gerações futuras”, parece ser um dos caminhos a ser adotado. (CAPRA, 2006, p. 15).

A compreensão de um sistema de produção e consumo sustentável implica, diretamente e genericamente, na questão da saúde do planeta. Especificamente, fala-se da saúde de cada componente da teia da vida. $\mathrm{O}$ direito ao meio ambiente equilibrado, não pode ser compreendido de modo restritivo, ou seja, esse direito não se restringe tão somente às condições 
sanitárias fora do local de trabalho, mas sim deve estar presente também no meio ocupacional. A exposição aos agentes agressivos, fruto da necessidade de acompanhar o mercado (no tocante à oferta/demanda) desencadeia a necessidade de desenvolver uma ética ocupacional sustentável.

Deste modo, ao se considerar os riscos ambientais, no sentido de agentes ambientais decorrentes de decisões do processo produtivo, o direito à saúde no meio ambiente de trabalho necessita ser visualizado sob a ótica da sustentabilidade. Prescinde de um conjunto de ações voltadas à identificação dos riscos, seu reconhecimento e eliminação e prevenção/precaução. É fato que as necessidades produtivas ditadas pela economia alteraram significativamente os ambientes de trabalho. As decisões em produção com exposição de risco à saúde sejam humanas ou de qualquer oura espécie indiretamente envolvida, provocam a necessidade de decisões em prevenção/ precaução às doenças do trabalho no meio ambiente de trabalho.

Para Nilton, pensar em soluções sobre o meio ambiente sustentável é pensar na vida do próximo, de modo que os direitos fundamentais garantidos pela Constituição Federal de 1988 possam, de fato, ser efetivos e não um resultado político de um determinado momento histórico. (NILTON, 2012, p. 272). O autor destaca, no texto constitucional de 1988, o art. 225, ao preconizar que o Meio Ambiente é "um bem de uso comum do povo e essencial à sadia qualidade de vida”, evidenciando, deste modo, "não apenas preocupação do Constituinte Originário com a preservação do planeta, mas importa em uma proteção mais ampla, porquanto o direito ao meio ambiente saudável está intrinsecamente vinculado aos direitos à vida e à saúde, ou seja, cuida aquele de um direito natural de preservação da própria espécie”. (NILTON, 2012, p. 272).

A noção corrente de sustentabilidade deriva justamente da necessidade de preservação dos ecossistemas diante do processo produtivo com o fim último de se alcançar um desenvolvimento compatível com a capacidade de sustentação e resiliência dos sistemas naturais tendo em vista os seus benefícios agregados para o bem-estar humano. (LOURENÇO, 2012, p.294)

Contudo, as pessoas estarão dispostas a pagar o preço da sustentabilidade? O que, afinal, significa pagar o preço? (LOURENÇO, 2012, p.285). Pode existir um desenvolvimento sustentável? Pode-se falar em produção de bens e desenvolvimento econômico capitalista sustentável capaz de preservar 
cada elemento que compõe a biosfera? E, ainda, é possível desenvolver uma ética ocupacional sustentável?

Os economistas corporativos tratam como bens gratuitos não somente o ar, a água e o solo, mas também a delicada teia das relações sociais, que é seriamente afetada pela expansão econômica contínua. Os lucros privados estão sendo obtidos com os custos públicos em detrimento do meio ambiente e da qualidade geral da vida, e às expensas das gerações futuras. O mercado, simplesmente, nos dá a informação errada. Há uma falta de realimentação, e a alfabetização ecológica básica nos ensina que esse sistema não é sustentável. (CAPRA, 2006, p. 219)

Hawken aponta que uma das maneiras mais eficientes para se mudar essa situação seria uma reforma ecológica dos impostos. Essa reforma seria estritamente neutra do ponto de vista da renda, deslocando o fardo das taxas dos impostos de renda para os "eco-impostos". Isso significa que seriam acrescentados impostos aos produtos, às formas de energia, aos serviços e aos materiais existentes, de maneira que os preços refletissem melhor os custos reais. (CAPRA, 2006, p. 219). Para Capra, o sucesso, numa reforma ecológica dos impostos, necessita de um processo lento e em longo prazo para proporcionar às novas tecnologias e aos novos padrões de consumo tempo suficiente para se adaptar, e os eco-impostos precisam ser aplicados com previsibilidade para encorajar inovações industriais. (CAPRA, 2006, p. 219).

Nas comunidades humanas, parceria significa democracia e poder pessoal, pois cada membro da comunidade desempenha um papel importante. Combinando o princípio da parceria com a dinâmica da mudança e do desenvolvimento, também podemos utilizar o termo “coevolução” de maneira metafórica nas comunidades humanas. À medida que uma parceria se processa, cada parceiro passa a entender melhor as necessidades dos outros. Numa parceria verdadeira, confiante, ambos os parceiros aprendem e mudam - eles coevoluem. Aqui, mais uma vez, notamos a tensão básica entre o desafio da sustentabilidade ecológica e a maneira pela qual nossas sociedades atuais são estruturadas, a tensão entre economia e a ecologia. A economia enfatiza a competição, a expansão e a dominação; ecologia enfatiza a cooperação, a conservação e a parceria. (CAPRA, 2006, p. 219).

O sociólogo Anthony Giddens indicou o valor básico do hábito nas práticas sociais e no autoentendimento ao alegar que só testamos nossas alternativas 
em relação aos hábitos que já dominamos.Imaginar uma vida de impulsos momentâneos, de ação a curto prazo, despida de rotinas sustentáveis, uma vida sem hábitos e imaginar na verdade uma existência irracional. (SENNETT, 2012, p. 49)

Reconectar-se com a teia da vida significa construir, nutrir e educar comunidades sustentáveis, nas quais podemos satisfazer nossas aspirações e nossas necessidades sem diminuir as chances das gerações futuras. Para realizar essa tarefa, podemos aprender valiosas lições extraídas do estudo de ecossistemas, que são comunidades sustentáveis de plantas, de animais e de microorganismos. Para compreender essas lições, precisamos aprender os princípios básicos da ecologia. Precisamos nos tornar, por assim dizer, ecologicamente alfabetizados. Ser ecologicamente alfabetizado, ou "eco-alfabetizado", significa entender os princípios de organização das comunidades ecológicas (ecossistemas) e usar esses princípios para criar comunidades humanas sustentáveis. Precisamos revitalizar nossas comunidades - inclusive nossas comunidades educativas, comerciais e políticas - de modo que os princípios da ecologia se manifestem nelas como princípios de educação, de administração e de política.(CAPRA, 2006, p. 218).

Entender a interdependência ecológica significa entender relações. Isso determina as mudanças de percepção que são características do pensamento sistêmico - das partes para o todo, de objetos para relações, de conteúdo para padrão. Uma comunidade humana sustentável está ciente das múltiplas relações entre seus membros. Nutrir a comunidade significa nutrir essas relações. (CAPRA, 2006, p. 219).

Naturalmente, há muitas diferenças entre ecossistemas e comunidades humanas. Nos ecossistemas não existe autopercepção, nem linguagem, nem consciência e nem cultura; portanto, neles não há justiça nem democracia; mas também não há cobiça nem desonestidade. Não podemos aprender algo sobre valores e fraquezas humanas a partir de ecossistemas. Mas o que podemos aprender, e devemos aprender com eles é como viver de maneira sustentável. Durante mais de três bilhões de anos de evolução, os ecossistemas do planeta têm se organizado de maneiras sutis e complexas, a fim de maximizar a sustentabilidade. Essa sabedoria da natureza é a essência da eco-alfabetização.(CAPRA, 2006, p. 218). 
Uma ética do meio ambiente acharia que poupar e reciclar recursos seria virtuoso e que o consumo extravagante e desnecessário seria uma depravação. Uma ética do meio ambiente rejeita os ideais de uma sociedade materialista, na qual o êxito é medido pelo número de artigos de consumo que uma pessoa consegue acumular e em seu lugar ajuíza o êxito em termos do desenvolvimento das potencialidades de cada qual e da conquista da autorrealização e da felicidade. Promove a frugalidade, na medida em que é necessária para minimizar a poluição e garantir que tudo pode ser reutilizado por inúmeras vezes. Colocar fora descuidosamente materiais que podem ser reciclados é uma forma de vandalismo, é roubar recursos do planeta que são nossa propriedade em comum. (SINGER, 2002).

A sustentabilidade envolve crescimento com desenvolvimento econômico, social e ambiental. (NILTON, 2012, p. 274). Os princípios do desenvolvimento sustentável e de uma ética ocupacional sustentável são a busca da coexistência harmônica entre economia e meio ambiente. Não se objetiva impedir o desenvolvimento econômico, o correto é que as atividades sejam desenvolvidas lançando-se mão dos instrumentos existentes adequados para a menor degradação possível do meio ambiente como um todo.

Os riscos das novas tecnologias emergentes e capazes de justificar imperativos de ação pública e privada de conteúdo precaucional, diante da proliferação de ameaças definidas por elevados graus de incerteza científica. (WOLKMER, 2012, p. 220-221). Curioso perceber que Bell escreveu que toda sociedade, em 1967, já estava conscientemente comprometida com o crescimento econômico, com a elevação do padrão de vida de seu povo e, portanto com o planejamento, direção e controle da mudança social.(BAUMAN, 2001, p.151).O encantamento moderno com o progresso - com a vida que pode ser "trabalhada” para ser mais satisfatória do que é - ainda não terminou, e não é provável que termine tão cedo. A modernidade não conhece outra vida senão a vida "feita”. (BAUMAN, 2001, p.155)

Quando nada, a condição humana no estágio da modernidade "fluida” ou do capitalismo "leve" tronou essa modalidade de vida ainda mais visível: o progresso não é mais uma medida temporária , uma questão transitória, que leva eventualmente (e logo) a um estado de perfeição (isto é, um estado em que o que quer que devesse ser feito terá sido feito e não será necessária qualquer mudança adicional), mas um desafio e uma necessidade perpétua e talvez sem fim, o verdadeiro significado de "permanecer vivo e bem". (BAUMAN, 2001, p.155). 
Canotilho, ao tratar da questão ambiental, enfatizou que as normas disciplinadoras de primeira geração objetivaram primordialmente o controle da poluição e a subjetivação do direito do meio ambiente como um direito fundamental do ser humano, numa perspectiva antropocêntrica, pautada na dignidade da espécie humana. (WOLKMER, 2012, p. 222-223). Bobbio destaca que ao lado dos direitos sociais emergiram os chamados direitos de terceira geração, sendo que o mais importante deles é o reivindicado pelos movimentos ecológicos: o direito de viver num ambiente não poluído. (BOBBIO, 1992).

O reconhecimento dos direitos fundamentais do homem em enunciados explícitos nas declarações de direitos estão longe de se esgotarem suas possibilidades, já que a cada passo na etapa da evolução da Humanidade importa na conquista de novos direitos. Eis mais uma razão para a convivência harmônica do homem para com a natureza e o seu local de trabalho.

Ainda que tenha sido redigida totalmente antropocêntrica, e assim seja, a Constituição Federal de 1988, no caput do artigo 225, garante o direito de todos ao meio ambiente ecologicamente equilibrado. Em seu capítulo sobre meio ambiente, a Carta Constitucional aborda o direito a um meio ambiente ecologicamente equilibrado como um bem essencial à sadia qualidade de vida. Ao elaborar tais dispositivos, o legislador não considerou apenas o meio ambiente de forma abstrata, mas preocupou-se com a estrita relação entre meio ambiente de trabalho e tutela da vida e saúde do trabalhador. Ademais, elenca no rol dos direitos sociais, em seu art. $6^{\circ}$, o direito à saúde, e no artigo $7^{\circ}$, inciso XXII, a redução dos riscos inerentes ao trabalho, por meio de normas de saúde, higiene e segurança. Tais direitos sociais pertencem ao grupo dos direitos fundamentais previstos na Constituição Federal.

Dentro da perspectiva de uma nova visão do Direito, em especial da Constituição Federal, Wolkmer e Leite propõem uma abordagem e um arranjo organizatório que enfatiza cada vez mais um compromisso estatal e social com a proteção do desenvolvimento da vida, situando a Constituição como uma fonte normativa aberta ao tempo e à cultura, responsável por um projeto existencial complexo, plural e que cada vez mais, suscita desafios ao modelo de repartição de tarefas ao artigo 225. Afinal, a realidade dos riscos ganhou complexidade adicional e exige que novo esforço seja realizado para sua compreensão e para a proposição de alternativas que sejam capazes de enfrentála, além de descrever experiências - estatísticas - que já se encontram em curso, e que possam ser situadas nessa abordagem que se impõe como desafio. (WOLKMER, 2012, p. 220-221). 
Os riscos de segunda geração requerem não só respostas no plano de proteção reforçada para as presentes e as futuras gerações, mas também projetos existenciais diferenciados, integrados em uma nova cultura constitucional que ganha importância nesse cenário, moralmente aberta e plural, capaz de integrar comunidades morais diferenciadas e de atender a demandas por proteção até então desconhecidas ou de tímida consideração, ao menos pela comunidade jurídica nacional. (WOLKMER, 2012, p. 220-221).

A melhoria da qualidade do meio ambiente está diretamente associada a uma mudança de postura, de atitude do homem frente aos problemas naturais e envolve o cultivo da consciência ecológica que reconhece a unidade de humanos, plantas, animais e a própria terra. LOURENÇO, 2012, p.299). Eis a essência da ecologia profunda. Permitir um desenvolvimento que contemple a preservação de todas as espécies e recursos naturais. Um progresso no qual as espécies não se autodestruam.

\section{CONSIDERAÇÕES FINAIS}

A realidade dos danos decorrentes do meio ambiente de trabalho está a exigir uma mudança de postura da espécie humana. O exame deve partir da perspectiva da proteção das espécies - aqui em específico o homem, sem cair na teoria antropocêntrica - dentro da teia da vida, no atual cenário em que se encontram. Se a ecologia profunda propõe a análise do meio ambiente integrado, onde todos os seres são interligados e com o mesmo grau de importância dentro do enredo de vida, a análise tenta resgatar e proteger a espécie do homem em face ao próprio homem. O resguardo do componente humano é em face da própria autodestruição no meio ambiente de trabalho.

O desenvolvimento de uma ética ambiental sustentável, capaz de reunir em seu rol de tutela, além de todas as espécies que compõe o sistema, a saúde e integridade do trabalhador, frente aos novos riscos decorrentes dos novos processos produtivos requer a visualização do homem como um elemento/parte integrante da sustentabilidade profunda.

A busca pela salubridade do meio ambiente de trabalho atinge a consciência ecológica profunda. Muito além de preservar uma espécie - humana - a diminuição e uso racional, no meio ocupacional, de novas substâncias e novas tecnologias, alcançada através de um consumidor mais consciente e prudente diminuirá, gradativamente, a produção de lixo, contaminação de 
efluentes, surgimento de novos riscos desconhecidos, permitindo a sobrevivência das demais espécies da teia da vida. Mais a frente de beneficiar o homem, a integridade da biosfera unicamente por si mesma, com todas suas espécies e elementos preservam-se.

Para que essa preservação ocorra, o homem deve partir da compreensão do valor inerente da natureza e dele enquanto apenas mais um elemento da teia da vida, com um direito humano ao meio ambiente ecologicamente equilibrado, assim como qualquer outra espécie, mas de forma a não cair na tentação da posição antropocêntrica. Isso somente seria possível a partir de uma mudança drástica de valores. A começar, por uma ética ocupacional sustentável, capaz privilegiar, na produção e consumo de bens, a totalidade do meio ambiente, com suas espécies e diversidades.

\section{REFERÊNCIAS}

ANTUNES, Ricardo. Adeus ao Trabalho? Ensaios sobre a Metamorfose e a Centralidade do Mundo do Trabalho. $6^{a}$ ed. São Paulo: Cortez, 1999.

BAUMAN, Zygmunt. Modernidade Líquida. Trad: Plínio Dentzien. Rio de Janeiro: Zahar, 2001.

BECK, Ulrich. Risk Society. Londres: Sage, 1992.

BECK, Ulrich. Sociedade de risco. Rumo a uma outra modernidade. Tradução de Sebastião Nascimento. São Paulo: Ed.34, 2010.

BOBBIO, Norberto. A Era dos Direitos. Rio de Janeiro: Campus, 1992.

BOLIS, Mónica. O Regulamento Internacional da Saúde. In: Revista de Direito Sanitário. Vol 4. São Paulo: LTR, 2003.

BRASIL. Previdência Social. Disponível em <http:// www.previdenciasocial.gov.br/estatísticas>. Acesso em 10 dez. 2010. Dos mais de trinta mil casos registrados junto a Previdência Social no ano de 2009, mais da metade decorreu da exposição a esse risco. 
CAPRA, Fritjof. A TEIA DA VIDA - Uma nova compreensão científica dos sistemas vivos. Tradução: Newton Roberval Eichemberg. Editora Cultrix: São Paulo, 2006.

CARVALHO, Délton Winter de. Dano ambiental futuro: a responsabilização civil pelo risco ambiental. Rio de Janeiro: Forense Universitária, 2008.

CASTELLS, Manuel. A sociedade em rede. São Paulo: Paz e Terra, 1999.

DERANI, C. Direito Ambiental Econômico. São Paulo, Max Limonad, 1997.

DEVALL, Bill; SESSIONS, George. Deep Ecology: living as IF nature mattered. Layton, Utah: Gibbs Simith. 1985, p. 70. In: LOURENÇO, Daniel Braga. OLIVEIRA, Fábio Corrêa Souza de. Sustentabilidade insustentável? In: FLORES, Nilton Cesar. A sustentabilidade Ambiental em suas múltiplas faces. São Paulo: Millennium, 2012.

FIGUEIREDO, Guilherme José Pavin de. Meio Ambiente. In: Revista de Direito Sanitário. Vol 4. São Paulo: LTR, 2003.

GIDDENS, Anthony. Sociology. Oxford: Polity Press, 1990.

HAWKEN (1993), pp. 177ss.; Daly (1995). In: Capra, Fritjof. A TEIA DA VIDA - Uma nova compreensão científica dos sistemas vivos. Tradução: Newton Roberval Eichemberg. Editora Cultrix: São Paulo, 2006.

\section{PREVIDÊNCIA. AEPS 2012 - SEÇÃO IV - ACIDENTES DO} TRABALHO - TABELAS. Disponível em: http://www.previdencia. gov.br/dados-abertos/aeps-2012-anuario-estatistico-da-previdencia-social2012/aeps-2012-secao-iv-acidentes-do-trabalho/aeps-2012-secao-ivacidentes-do-trabalho-tabelas/. Acesso em jun/2015.

LOURENÇO, Daniel Braga. OLIVEIRA, Fábio Corrêa Souza de. Sustentabilidade insustentável? In: FLORES, Nilton Cesar. A sustentabilidade Ambiental em suas múltiplas faces. São Paulo: Millennium, 2012. 
MAGALHÃES, José Luiz Quadros de. Capitalismo Guerra e Meio Ambiente. In: Juris Poiesis. Revista do Curso de Direito da Universidade Estácio de Sá. Rio de Janeiro, Ano 15, nº 15.

NILTON, Cesar Flores. Inovação Tecnológica e Desenvolvimento Sustentável. In: A sustentabilidade ambiental em suas múltiplas faces.Millennium: São Paulo, 2012.

REIMBERG, Cristiane Oliveira. Prevenir Sempre. In: Revista Proteção. Março/2011 - Ano XXIV.

ROCHA, Júlio César de Sá da. Direito Ambiental do Trabalho. São Paulo: LTr, 2002.

SANTOS, Boaventura de Sousa. A Globalização e as Ciências Sociais. $3^{\mathrm{a}}$ ed. São Paulo: Cortez, 2002.

SENNETT, Richard. A corrosão do caráter. Tradução de Marcos Santarrita. $1^{\text {a }}$ ed. Rio do Janeiro: BestBolso, 2012.

SINGER, Peter. Ética prática. UNESP.

WOLKMER, Antonio Carlos; LEITE, José Rubens Morato. Os novos direitos no Brasil: natureza e perspectivas - uma visão básica das novas conflituosidades jurídicas. $2^{\mathrm{a}}$ ed. São Paulo: Saraiva.

Artigo recebido em: 28/03/2015 Aprovado para publicação em: 11/08/2015

Como citar: FLORES, Nilton Cesar. TERRIBLE, Daniele Regina. Ética ocupacional sustentável numa sociedade globalizada. Revista do Direito Público. Londrina, v.10, n.2, p.89-110, mai./ago. 2015. DOI: 10.5433/1980510X.2015v10n2p89. 